\title{
บUisuersily
}

\section{Sleep problems and subjective cognitive complaints among middle-aged and older adults in 45 low- and middle-income countries}

Smith, L., Oh, H., Jacob, L., López-Sánchez, G. F., Veronese, N., Soysal, P., Shin, J. I., Schuch, F., Tully, M. A., Butler, L., Barnett, Y., \& Koyanagi, A. (2022). Sleep problems and subjective cognitive complaints among middle-aged and older adults in 45 low- and middle-income countries. Aging Clinical and Experimental Research , 34, 1285-1293. https://doi.org/10.1007/s40520-021-02052-1

Link to publication record in Ulster University Research Portal

\section{Published in:}

Aging Clinical and Experimental Research

\section{Publication Status:}

Published online: 05/01/2022

DOI:

10.1007/s40520-021-02052-1

\section{Document Version}

Author Accepted version

\section{General rights}

Copyright for the publications made accessible via Ulster University's Research Portal is retained by the author(s) and / or other copyright owners and it is a condition of accessing these publications that users recognise and abide by the legal requirements associated with these rights.

\section{Take down policy}

The Research Portal is Ulster University's institutional repository that provides access to Ulster's research outputs. Every effort has been made to ensure that content in the Research Portal does not infringe any person's rights, or applicable UK laws. If you discover content in the Research Portal that you believe breaches copyright or violates any law, please contact pure-support@ulster.ac.uk. 
Title: Sleep problems and subjective cognitive complaints among middle-aged and older adults in 45 low- and middle-income countries

Lee Smith ${ }^{1}, \mathrm{PhD}$, Hans $\mathrm{Oh}^{2}, \mathrm{PhD}$, Louis Jacob ${ }^{3,4,5}, \mathrm{MD}, \mathrm{PhD}$, Guillermo F. López-Sánchez ${ }^{6 *}$, PhD, Nicola Veronese ${ }^{7}, \mathrm{MD}$, Pinar Soysal ${ }^{8}, \mathrm{MD}, \mathrm{PhD}$, Jae Il Shin ${ }^{9}, \mathrm{MD}, \mathrm{PhD}$, Felipe Schuch $^{10}, \mathrm{PhD}$, Mark A Tully ${ }^{11}, \mathrm{PhD}$, Laurie Butler ${ }^{1}, \mathrm{PhD}$, Yvonne Barnett ${ }^{1}, \mathrm{PhD}, \mathrm{Ai}$ Koyanagi $^{3,4,12}, \mathrm{MD}, \mathrm{PhD}$

1. Centre for Health, Performance and Wellbeing, Anglia Ruskin University, Cambridge, CB1 1PT, UK.

2. Suzanne Dworak-Peck School of Social Work, University of Southern California, CA, USA.

3. Research and Development Unit, Parc Sanitari Sant Joan de Déu, Dr. Antoni Pujadas, 42, Sant Boi de Llobregat, Barcelona 08830, Spain.

4. Centro de Investigación Biomédica en Red de Salud Mental (CIBERSAM), Madrid, Spain.

5. Faculty of Medicine, University of Versailles Saint-Quentin-en-Yvelines, Montignyle-Bretonneux 78180, France.

6. Vision and Eye Research Institute, School of Medicine, Faculty of Health, Education, Medicine and Social Care, Anglia Ruskin University-Cambridge Campus, Cambridge, UK.

7. Department of Internal Medicine, Geriatrics Section, University of Palermo, Palermo, Italy.

8. Department of Geriatric Medicine, Faculty of Medicine, Bezmialem Vakif University, Adnan Menderes Bulvarı (Vatan Street), 34093 Fatih, İstanbul, Turkey. 
9. Department of Pediatrics, Yonsei University College of Medicine, Seoul, South Korea.

10. Department of Sports Methods and Techniques, Federal University of Santa Maria, Santa Maria, Brazil.

11. School of Health Sciences, Institute of Mental Health Sciences, Ulster University, Newtownabbey BT37 0QB, Northern Ireland, UK.

12. ICREA, Pg. Lluis Companys 23, 08010, Barcelona, Spain.

* Corresponding author:

Dr. Guillermo F. López-Sánchez. guillermo.lopez-sanchez@aru.ac.uk 


\section{ABSTRACT}

Background: Currently, a small body of evidence suggests that sleep problems are positively associated with subjective cognitive complaints (SCC). However, no studies on this topic exist from low- and middle-income countries (LMICs). Thus, we investigated the association between sleep problems and SCC in a large sample of middle-age and older adults from 45 LMICs.

Methods: Cross-sectional, predominantly nationally representative, community-based data were analyzed from the World Health Survey. Sleep problems (such as difficulties falling asleep, waking up frequently during the night or waking up too early in the morning) in the last 30 days were self-reported. Two questions on subjective memory and learning complaints in the past 30 days were used to create a SCC scale ranging from 0 (No SCC) to 100 (worse SCC). Multivariable linear regression was conducted to explore the association between sleep problems (exposure) and SCC (outcome).

Results: Data on 60,228 adults aged $\geq 50$ years were analyzed [mean (SD) age 61.4 (9.9) years; $53.9 \%$ females]. After adjustment for potential confounders, compared to those without sleep problems, the mean SCC score for the multivariable model was 13.32 $(95 \% \mathrm{CI}=12.01,14.63), 19.46(95 \% \mathrm{CI}=17.95,20.98), 24.17(95 \% \mathrm{CI}=22.02,26.33)$, and $31.39(95 \% \mathrm{CI}=28.13,34.65)$ points higher for mild, moderate, severe, and extreme sleep problems, respectively. Similar results were found for analyses stratified by age and countryincome level.

Conclusion: Sleep problems were positively associated in a dose-response manner with SCC among middle-aged and older adults in multiple LMICs. Addressing sleep problems may aid in the prevention of SCC and ultimately dementia, pending future longitudinal research. 
Key words: Sleep problems; Subjective cognitive complaints; Low- and middle-income countries; Older adults 


\section{INTRODUCTION}

Dementia is a syndrome in which there is deterioration in memory, thinking, behavior and the ability to perform everyday activities [1]. Dementia is most common among older adults with $5-8 \%$ of the global population aged $\geq 60$ years reported to have dementia [1], and almost $60 \%$ of those with dementia live in low- and middle-income countries (LMICs) [1]. Subjective cognitive complaints (SCC) refer to everyday concerns (e.g., in relation to memory and/or other cognitive functions) cited by people both with and without objective evidence of cognitive impairment [2], and has been found to be a strong predictor of dementia.

One systematic review consisting of 17 studies found that SCC (compared to no SCC) were associated with a significantly higher risk of progression to dementia [3], while, another meta-analysis suggested that older people with subjective memory complaints with no objective deficits are twice as likely to develop dementia as individuals without subjective memory complaints [4]. Furthermore, based on another review, it was concluded that individuals with SCC are at increased risk of progression to Alzheimer's disease, and that there is evidence that those with SCC have a higher prevalence of positive biomarkers for amyloidosis and neurodegeneration [5].

Interestingly, sleep problems may lead to poor cognition via, for example, abnormalities in sleep architecture that interferes with sleep-dependent memory consolidation, thus contributing to memory impairment [6]. In one study of 351 African American older adults, it was found that worse overall sleep quality was significantly associated with subjective reports of difficulty recalling the placement of objects, recalling specific facts from reading materials, and worse memory currently compared to the past. Specifically, participants classified as poor sleepers (Pittsburgh Sleep Quality Index [PSQI] total score > 5) were more 
likely to report worse current memory compared to the past than participants classified as good sleepers (PSQI total score $\leq 5$ ) [7]. In another study consisting of 1011 subjects aged 65 years from France, a significant association was found between subjective cognitive and sleep complaints, and daytime sleepiness [8]. Furthermore, a study including 2,962 US middle to older age adults found that people with SCC were more likely to have sleep apnea or other sleep disturbances [9].

To the authors knowledge, no other studies exist on the association between sleep problems and SCC. It is worth noting that the existing literature has key shortcomings. First, all studies were carried out in high-income settings, despite the fact that the majority of people with dementia live in LMICs [1]. It has been suggested that use of domestic and public lighting and other environmental factors related to the sleep site shape sleep patterns [10]. Thus, it is possible that findings from high-income countries are not generalizable to LMICs, which are environmentally distinct with generally much higher proportions of rural populations [11]. Next, all studies have utilized relatively small sample sizes [7-9] and are single country studies [7-9]. Multi-country studies consisting of large and representative samples are required as multi-country studies allow for the comparison of standardized estimates across different settings.

Given this background, the aim of the present study was to investigate the association between sleep problems and SCC in a sample of 60,228 adults aged $\geq 50$ years from 45 LMICs.

\section{METHODS}


The World Health Survey (WHS) was a cross-sectional survey carried out in 70 countries in 2002-2004. Single-stage random sampling was undertaken in 10 countries, while stratified multi-stage random cluster sampling was conducted in 60 countries. Survey details are available elsewhere (http://www.who.int/healthinfo/survey/en/). In brief, individuals with a valid home address aged $\geq 18$ years were eligible to participate. Kish tables were used so that all household members had an equal chance of being selected. The questionnaire was subject to standard translation procedures to ensure comparability. Information was obtained through face-to-face interviews and telephone interviews conducted by trained interviewers. Across all countries, the individual response rate was $98.5 \%$ [12]. To adjust for non-response, sampling weights were generated using the population distribution as reported by the United Nations Statistical Division. Ethical approval for the survey was provided by ethical boards at each study site. All participants gave their informed consent.

\section{Subjective cognitive complaints (SCC)}

SCC were assessed with two questions: (a) Overall in the last 30 days, how much difficulty did you have with concentrating or remembering things?; and (b) In the last 30 days, how much difficulty did you have in learning a new task (for example, learning how to get to a new place, learning a new game, learning a new recipe etc.)? [13]. Each item was scored on a five-point scale: none $(\operatorname{code}=1)$, mild $(\operatorname{code}=2)$, moderate $(\operatorname{code}=3)$, severe $(\operatorname{code}=4)$, and extreme/cannot do $($ code $=5)$. Since these answer options were an ordered categorical scale, as in previous WHS studies, we conducted factor analysis with polychoric correlations to incorporate the covariance structure of the answers provided for individual questions measuring a similar construct [14-17]. The principal component method was used for factor extraction, while factor scores were obtained using the regression scoring method. The choice of a one factor solution was justified by the high eigenvalue of the first factor and the high 
communalities of the original variables. These factor scores were later converted to scores ranging from 0-100 to create a SCC scale with higher values representing more severe cognitive complaints.

\section{Sleep problems}

Sleep problems were assessed by the question: "Overall in the last 30 days, how much of a problem did you have with sleeping, such as falling asleep, waking up frequently during the night or waking up too early in the morning?", with answer options "None", "Mild", "Moderate", "Severe", and "Extreme". For some specific analyses, we used a dichotomized variable of severe/extreme or not [18].

\section{Control variables}

The control variables were selected based on past literature [7], and included age, sex, highest level of education achieved (no formal, primary, secondary, tertiary), depression, and perceived stress. Depression referred to having had past 12-month depression assessed by questions from the World Mental Health Survey version of the Composite International Diagnostic Interview [19]. Stress over the month prior to the interview was assessed by two questions from the Perceived Stress Scale [20]: "How often have you felt that you were unable to control the important things in your life?"; and "How often have you found that you could not cope with all the things that you had to do?" The answer options to these questions were: never $($ score $=1)$, almost never $($ score $=2)$, sometimes $($ score $=3)$, fairly often $($ score $=4)$, very often (score=5). Factor analysis with polychoric correlations was conducted to create a scale ranging from 0 to 100 with higher scores representing greater levels of stress.

\section{Statistical analysis}


Data were publicly available for 69 countries. Of these, 10 countries were excluded due to a lack of sampling information. Furthermore, 10 high-income countries were excluded in order to focus on LMICs. Moreover, Turkey was deleted due to lack of data on education, while Brazil, Hungary, and Zimbabwe were omitted due to lack of data on perceived stress. Thus, the final sample consisted of 45 LMICs according to the World Bank classification at the time of the survey (2003). The data were nationally representative for all countries with the exception of China, Comoros, the Republic of Congo, Ivory Coast, India, and Russia.

Statistical analyses were performed with Stata 14.1 (Stata Corp LP, College station, Texas). The analysis was restricted to those aged $\geq 50$ years to focus on the middle-aged (i.e., 50-64 years) and older ( $\geq 65$ years) population. The middle-aged was also included in our study as from the point of prevention of dementia, intervening in middle-age is now considered important [21], especially that cognitive dysfunction can manifest up to 10 years before a dementia diagnosis [22].

Multivariable linear regression analysis was conducted to assess the association between sleep problems (exposure) and SCC score (outcome). Analyses were conducted for the overall sample and also for age (50-64 and $\geq 65$ years) or country-income level (low-income countries and middle-income countries) stratified samples. This analysis used the fivecategory sleep problems variable (i.e., none, mild, moderate, severe, extreme). Next, country-wise multivariable linear regression analysis was conducted to assess the association between severe/extreme sleep problems (exposure) and SCC score (outcome). Analyses using the overall sample and samples by age group were conducted. In order to assess the betweencountry heterogeneity that may exist in these associations, we calculated the Higgins' $I^{2}$ based on estimates for each country. The Higgins' $I^{2}$ represents the degree of heterogeneity that is 
not explained by sampling error with a value of $<40 \%$ often considered as negligible and 40 $60 \%$ as moderate heterogeneity [23]. The pooled estimate overall and by country-income levels was obtained by meta-analysis with random effects.

All regression analyses were adjusted for age, sex, education, depression, perceived stress, and country with the exception of the country-wise analysis which was not adjusted for country. Adjustment for country was done by including dummy variables in the models as in previous WHS publications [24, 25]. The sample weighting and the complex study design were taken into account in all analyses. Results from the linear regressions are presented as bcoefficients with $95 \%$ confidence intervals (CIs). The level of statistical significance was set at $\mathrm{P}<0.05$.

\section{RESULTS}

The analytical sample included 60,228 adults aged $\geq 50$ years from 45 LMICs (age 50-64 years $n=30,868$; age $\geq 65$ years $n=23360$ ). The included countries and their sample sizes are provided in Table $\mathbf{S 1}$ of the Appendix. The sample characteristics are provided in Table $\mathbf{1 .}$ The mean (SD) age was $61.4(9.9)$ years and 53.9\% were females. The prevalence of sleep problems overall was $24.3 \%$ (mild), $18.4 \%$ (moderate), $11.8 \%$ (severe), and $2.4 \%$ (extreme). The mean SCC score increased linearly with increasing severity of sleep problems regardless of age group (Figure 1). The mean SCC score was 19 in those without sleep problems, but this increased to 65.4 in those with extreme sleep problems. After adjustment for several potential confounders, compared to those without sleep problems, the mean SCC score was $13.32(95 \% \mathrm{CI}=12.01,14.63), 19.46(95 \% \mathrm{CI}=17.95,20.98), 24.17(95 \% \mathrm{CI}=22.02,26.33)$, and $31.39(95 \% \mathrm{CI}=28.13,34.65)$ points higher for mild, moderate, severe, and extreme sleep problems, respectively (Table 2). Similar results were found for analyses stratified by age 
and country-income level. The country-wise association between severe/extreme sleep problems and SCC score in adults aged $\geq 50$ years is shown in Figure 2. The pooled estimate for all countries was $13.96(95 \% \mathrm{CI}=12.47-15.45)$ with a moderate level of between-country heterogeneity $\left(I^{2}=58.6 \%\right)$. Pooled estimates for low-income countries and middle-income countries were $15.93\left(95 \% \mathrm{CI}=13.42,18.43 ; I^{2}=63.6 \%\right)$ and $12.55(95 \% \mathrm{CI}=10.82,14.27$; $I^{2}=47.9 \%$ ), respectively. The estimates for those aged 50-64 years (Figure S1 of the Appendix) and $\geq 65$ years (Figure $\mathbf{S} 2$ of the Appendix) were similar.

\section{DISCUSSION}

\section{Main findings}

In this large predominantly nationally representative sample of adults aged $\geq 50$ years from 45 LMICs, in the multivariable linear regression model, it was found that compared to those without sleep problems, the mean SCC score was 13.32 (95\%CI=12.01-14.63), 19.46 $(95 \% \mathrm{CI}=17.95-20.98), 24.17(95 \% \mathrm{CI}=22.02-26.33)$, and $31.39(95 \% \mathrm{CI}=28.13-34.65)$ points higher for mild, moderate, severe, and extreme sleep problems, respectively. The results were similar for middle-aged and older adults. Furthermore, severe/extreme sleep problems were significantly associated with worse SCC in most individual countries included in the study.

\section{Interpretation of findings}

Findings from the present study both support the limited previous literature by confirming that an association exists between sleep problems and SCC [7-9], and add to the existing literature by demonstrating for the first time that such an association also holds among middle-aged and older adults in a very large sample across multiple LMICs. 
There are several plausible pathways that likely explain the relationship between sleep problems and SCC. First, sleep problems (specifically short sleep duration) have been found to be associated with greater age-related brain atrophy and cognitive decline 2 years later [26]. Such brain atrophy may be owing to sleep problems resulting in shrinkage of large neurons, loss of myelinated axonal fibers, deafferentation, and reduction in synaptic density $[27,28]$. Second, sleep has been found to facilitate overnight memory consolidation, and sleep problems can thus inhibit this process [29]. Third, sleep problems are associated with a poor diet (e.g. higher intakes of confectionary and sugar) and lower levels of physical activity $[30,31]$, both of which have been implicated in SCC [32, 33]. Indeed, sleep problems may lead to poor diet owing to stimulating hunger and/or suppressing satiety signals. Insufficient sleep leads to orexigenic changes in both subjective and objective measures of hunger and fullness [30]. Moreover, poor sleep may lead to lower levels of physical activity owing to fatigue; however, this hypothesis has yet to be investigated.

Interestingly, although a positive association between severe/extreme problems and SCC was observed across all countries included in the study, the strength of the association was moderately different $\left(I^{2}=58.6 \%\right)$. Overall, the strength of the association was stronger in lowincome countries than in middle-income countries, but country-income level may not be a main determinant of the between-country heterogeneity as there was a moderate level of heterogeneity within low-income or middle-income countries. Previous studies have shown that technological, demographic, cultural and geographical differences may influence sleep quality and its association with health status at the population level [11]. Thus, it is possible that sleep problems are associated with other behavioral factors which can lead to greater SCC (e.g., lower physical activity, poor diet) differentially by setting or that this may be explained by the proportion of people who are taking medications to facilitate sleep (e.g., 
benzodiazepines), which have been reported to be associated with cognitive impairment [34]. However, future studies are warranted to understand the reason why the magnitude of the association differs by country.

\section{Public health and clinical implications}

Data from the present study suggest that sleep problems in LMICs are associated with SCC, and that addressing sleep problems may reduce risk for SCC, although future longitudinal studies are warranted. In a recent meta-analysis, it was concluded that interventions targeting cognitive and behavioral self-regulation (e.g., stress management/relaxation; meditation; controlled breathing; and stimulus control) improves sleep quality in adults without clinical sleep disorder [35]. Future studies should assess which type of intervention would be most suitable for LMICs where resources are limited. This is likely to improve other parameters of population health as sleep problems or insomnia have been associated with other adverse health outcomes such as increased risk for cardiovascular disease [36].

Moreover, clinicians should be aware of the high risk for SCC among those with sleep problems and attempt to address sleep problems whenever possible in middle-aged and older adults to prevent SCC, as SCC are not only associated with higher risk for dementia but other deleterious outcomes such as lower quality of life [37], fractures, falls, increased health care utilization [38], and premature mortality [39]. Finally, SCC can identify subtle changes in everyday functioning that could be a precursor for more serious cognitive decline and functioning, which may not be detected otherwise, and can more easily be measured than objective cognitive function [40]. Thus, this can be a potentially useful tool to identify people with sleep problems who are at increased risk for cognitive decline especially in LMICs where resources are limited, pending future research. Finally, although the present study 
focused exclusively on LMICs, the overarching body of literature indeed suggests that it is important to examine the relationship between sleep problems and SCCs, and address these problems independently of country income level.

\section{Strength and limitations}

The large predominantly nationally representative sample of middle-aged and older adults from 45 LMICs are clear strengths of the present study. However, findings must be interpreted considering the study limitations. First, the study was cross-sectional in nature, and the direction of the association cannot be confirmed. For example, it may be possible that SCC leads to worries, and in turn, this may disturb sleep. Future studies of a longitudinal nature are required to investigate the direction of the association. Second, sleep problems and SCC were both self-reported, potentially introducing reporting bias into the findings. Third, data on different types of sleep problems were not collected and it may be that the sleep problem-SCC relationship may differ depending on the type of sleep problem. Finally, two questions on SCC were used in our study but there is currently no consensus on the best measure for SCC, and previous studies have used a single question to a complex assessment involving multiple questions. Therefore, the use of a different measure of SCC could have yielded different results.

\section{Conclusion}

In this large sample of adults aged $\geq 50$ years from 45 LMICs, it was found that sleep problems were positively associated with SCC. If confirmed by longitudinal studies, addressing sleep problems may aid in the prevention of SCC and ultimately dementia. 
Compliance with Ethical Standards: The study was performed in accordance with the ethical standards as laid down in the 1964 Declaration of Helsinki and its later amendments.

Ethical approval: Ethical approval for the survey was provided by ethical boards at each study site.

Informed consent: All participants gave their informed consent.

\section{Conflict of Interest: None.}

Funding: None.

\section{REFERENCES}

1. World Health Organization (2021) Dementia. https://www.who.int/news-room/factsheets/detail/dementia. Accessed 8 November 2021.

2. Mitchell AJ (2008) Is it time to separate subjective cognitive complaints from the diagnosis of mild cognitive impairment? Age Ageing 37(5):497-9.

3. Mendonça MD, Alves L, Bugalho P (2016) From subjective cognitive complaints to dementia: Who is at risk?: A systematic review. Am J Alzheimers Dis Other Demen 31(2):105-14.

4. Mitchell AJ, Beaumont H, Ferguson D, Yadegarfar M, Stubbs B (2014) Risk of dementia and mild cognitive impairment in older people with subjective memory complaints: Metaanalysis. Acta Psychiatr Scand 130(6):439-51.

5. Studart A, Nitrini R (2016) Subjective cognitive decline: The first clinical manifestation of alzheimer's disease? Dementia \& Neuropsychologia 10:170-7.

6. Westerberg CE, Mander BA, Florczak SM, Weintraub S, Mesulam M, Zee PC, et al. (2012) Concurrent impairments in sleep and memory in amnestic mild cognitive impairment. J Int Neuropsychol Soc 18(3):490-500.

7. Gamaldo AA, Wright RS, Aiken-Morgan AT, Allaire JC, Thorpe Jr RJ, Whitfield KE (2019) The association between subjective memory complaints and sleep within older african american adults. J Gerontol B Psychol Sci Soc Sci. 74(2):202-11.

8. Tardy M, Gonthier R, Barthelemy J, Roche F, Crawford-Achour E (2015) Subjective sleep and cognitive complaints in 65 year old subjects: A significant association. the PROOF cohort. J Nutr Health Aging 19(4):424-30.

9. Van Patten R, Nguyen TT, Mahmood Z, Lee EE, Daly RE, Palmer BW, et al (2021) Physical and mental health characteristics of 2,962 adults with subjective cognitive complaints. The International Journal of Aging and Human Development.

00914150211026548. 
10. Ohayon MM, Milesi C (2016) Artificial outdoor nighttime lights associate with altered sleep behavior in the american general population. Sleep 39(6):1311-20.

11. Simonelli G, Marshall NS, Grillakis A, Miller CB, Hoyos CM, Glozier N (2018) Sleep health epidemiology in low and middle-income countries: A systematic review and metaanalysis of the prevalence of poor sleep quality and sleep duration. Sleep Health 4(3):239-50.

12. Nuevo R, Chatterji S, Verdes E, Naidoo N, Arango C, Ayuso-Mateos JL (2012) The continuum of psychotic symptoms in the general population: A cross-national study.

Schizophr Bull 38(3):475-85.

13. Ghose B, Abdoul Razak MY (2017) Memory and learning complaints in relation to depression among elderly people with multimorbidity. Geriatrics 2(2):15.

14. Koyanagi A, Vancampfort D, Carvalho AF, DeVylder JE, Haro JM, Pizzol D, et al (2017) Depression comorbid with tuberculosis and its impact on health status: Crosssectional analysis of community-based data from 48 low-and middle-income countries. BMC med 15(1):209.

15. Stubbs B, Koyanagi A, Thompson T, Veronese N, Carvalho AF, Solomi M, et al (2016) The epidemiology of back pain and its relationship with depression, psychosis, anxiety, sleep disturbances, and stress sensitivity: Data from 43 low-and middle-income countries. Gen Hosp Psychiatry 43:63-70.

16. Nuevo R, Van Os J, Arango C, Chatterji S, Ayuso-Mateos JL (2013) Evidence for the early clinical relevance of hallucinatory-delusional states in the general population. Acta Psychiatr Scand 127(6):482-93.

17. Moussavi S, Chatterji S, Verdes E, Tandon A, Patel V, Ustun B (2007) Depression, chronic diseases, and decrements in health: Results from the world health surveys. The Lancet 370(9590):851-8.

18. Koyanagi A, Stickley A (2015) The association between sleep problems and psychotic symptoms in the general population: A global perspective. Sleep. 38(12):1875-85.

19. Kessler RC, Üstün TB (2004) The world mental health (WMH) survey initiative version of the world health organization (WHO) composite international diagnostic interview (CIDI). Int. J. Methods Psychiatr. Res. 13(2):93-121.

20. Cohen S, Kamarck T, Mermelstein R (1983) A global measure of perceived stress. J Health Soc Behav 24.

21. Prince M, Comas-Herrera A, Knapp M, Guerchet M, Karagiannidou M (2016) World alzheimer report 2016: Improving healthcare for people living with dementia: Coverage, quality and costs now and in the future.

22. Amieva H, Jacqmin-Gadda H, Orgogozo J, Le Carret N, Helmer C, Letenneur L, et al. (2005) The 9 year cognitive decline before dementia of the alzheimer type: A prospective population-based study. Brain 128(5):1093-101. 
23. Higgins JP, Thompson SG. Quantifying heterogeneity in a meta-analysis. Stat Med (2002) 21(11):1539-58.

24. Stubbs B, Koyanagi A, Veronese N, Vancampfort D, Solmi M, Gaughran F, et al. (2016) Physical multimorbidity and psychosis: Comprehensive cross sectional analysis including 242,952 people across 48 low-and middle-income countries. BMC med 14(1):1-12.

25. Koyanagi A, Oh H, Stickley A, Haro JM, DeVylder J (2016) Risk and functional significance of psychotic experiences among individuals with depression in 44 low-and middle-income countries. Psychol Med 46(12):2655-65.

26. Lo JC, Loh KK, Zheng H, Sim SK, Chee MW (2014) Sleep duration and age-related changes in brain structure and cognitive performance. Sleep 37(7):821.

27. Pakkenberg B, Pelvig D, Marner L, Bundgaard MJ, Gundersen HJG, Nyengaard JR, et al. (2003) Aging and the human neocortex. Exp Gerontol 38(1-2):95-9.

28. Sexton CE, Storsve AB, Walhovd KB, Johansen-Berg H, Fjell AM (2014) Poor sleep quality is associated with increased cortical atrophy in community-dwelling adults. Neurology 83(11):967-73.

29. Rasch B, Born J (2013) About sleep's role in memory. Physiol Rev. 93(2): 681-766.

30. Zuraikat FM, Makarem N, Liao M, St-Onge M, Aggarwal B (2020) Measures of poor sleep quality are associated with higher energy intake and poor diet quality in a diverse sample of women from the go red for women strategically focused research network. J. Am. Heart Assoc. 9(4):e014587.

31. Kline CE (2014) The bidirectional relationship between exercise and sleep: Implications for exercise adherence and sleep improvement. Am. J. Lifestyle Med. 8(6):375-9.

32. Nemoto Y, Sato S, Takahashi M, Takeda N, Matsushita M, Kitabatake Y, et al (2018) The association of single and combined factors of sedentary behavior and physical activity with subjective cognitive complaints among community-dwelling older adults: Crosssectional study. PLoS One 13(4):e0195384.

33. Yuan C, Fondell E, Bhushan A, Ascherio A, Okereke OI, Grodstein F, et al (2019) Longterm intake of vegetables and fruits and subjective cognitive function in US men. Neurology 92(1):e63-75.

34. Stewart SA (2005) The effects of benzodiazepines on cognition. J Clin Psychiatry 66(2):9-13.

35. Murawski B, Wade L, Plotnikoff RC, Lubans DR, Duncan MJ (2018) A systematic review and meta-analysis of cognitive and behavioral interventions to improve sleep health in adults without sleep disorders. Sleep Med. Rev. 40:160-9.

36. Javaheri S, Redline S (2017) Insomnia and risk of cardiovascular disease. Chest 152(2):435-44. 
37. Hill NL, McDermott C, Mogle J, Munoz E, DePasquale N, Wion R, et al (2017) Subjective cognitive impairment and quality of life: A systematic review. Int. Psychogeriatr. 29(12):1965-77.

38. Al-Sari UA, Tobias JH, Archer H, Clark EM (2017) Do subjective memory complaints predict falls, fractures and healthcare utilization? A two-year prospective study based on a cohort of older women recruited from primary care. Int J Geriatr Psychiatry 32(9):968-76.

39. Ayalon L (2008) Subjective cognitive functioning as a predictor of all cause mortality in an israeli national sample of community dwelling older adults. Int J Geriatr Psychiatry 23(8):830-6.

40. Hohman TJ, Beason-Held LL, Lamar M, Resnick SM (2011) Subjective cognitive complaints and longitudinal changes in memory and brain function. Neuropsychology 25(1):125. 
Table 1 Sample characteristics (overall and by age)

\begin{tabular}{|c|c|c|c|c|}
\hline \multirow[b]{2}{*}{ Characteristic } & & \multicolumn{3}{|c|}{ Age } \\
\hline & & Overall & 50-64 years & $\geq 65$ years \\
\hline Age (years) & Mean (SD) & $61.4(9.9)$ & $55.6(4.4)$ & $72.1(7.0)$ \\
\hline \multirow[t]{2}{*}{ Sex } & Female & 53.9 & 52.6 & 56.2 \\
\hline & Male & 46.1 & 47.4 & 43.8 \\
\hline \multirow[t]{4}{*}{ Education } & No formal & 40.3 & 39.7 & 41.5 \\
\hline & Primary & 27.2 & 26.3 & 28.7 \\
\hline & Secondary & 24.2 & 24.7 & 23.4 \\
\hline & Tertiary & 8.3 & 9.3 & 6.4 \\
\hline \multirow[t]{2}{*}{ Depression } & No & 90.4 & 91.7 & 88.1 \\
\hline & Yes & 9.6 & 8.3 & 11.9 \\
\hline Perceived stress ${ }^{\mathrm{a}}$ & Mean (SD) & $40.6(29.3)$ & $39.2(28.2)$ & $43.3(31.1)$ \\
\hline SCC score ${ }^{b}$ & Mean (SD) & $33.1(31.7)$ & $27.5(28.9)$ & $43.3(34.0)$ \\
\hline \multirow[t]{5}{*}{ Sleep problems } & None & 43.1 & 48.4 & 33.3 \\
\hline & Mild & 24.3 & 24.2 & 24.4 \\
\hline & Moderate & 18.4 & 16.1 & 22.6 \\
\hline & Severe & 11.8 & 9.3 & 16.4 \\
\hline & Extreme & 2.4 & 1.9 & 3.3 \\
\hline
\end{tabular}

Abbreviation: SCC Subjective cognitive complaints; SD Standard deviation

Data are \% unless otherwise stated.

${ }^{\mathrm{a}}$ The perceived stress score ranged from 0 to 100 with higher scores representing greater perceived stress.

${ }^{\mathrm{b}}$ The outcome (subjective cognitive complaints score) ranged from 0 to 100 with higher scores representing greater cognitive complaints. 
Table 2 Association between sleep problems (or covariates) and subjective cognitive complaints (outcome) estimated by multivariable linear regression

\begin{tabular}{|c|c|c|c|c|c|c|}
\hline Characteristic & & Overall & Age 50-64 years & Age $\geq 65$ years & LICs & MICs \\
\hline \multirow[t]{9}{*}{ Sleep problems } & None & Ref. & Ref. & Ref. & Ref. & Ref. \\
\hline & Mild & $13.32 * *$ & $14.50 * *$ & $10.90 * *$ & $14.59 * *$ & $11.33 * *$ \\
\hline & & {$[12.01,14.63]$} & {$[12.96,16.05]$} & {$[7.87,13.92]$} & {$[12.61,16.57]$} & {$[10.00,12.66]$} \\
\hline & Moderate & $19.46^{* *}$ & $19.61 * *$ & $18.63 * *$ & $19.13^{* *}$ & $19.50 * *$ \\
\hline & & {$[17.95,20.98]$} & {$[17.93,21.30]$} & {$[15.44,21.82]$} & {$[16.78,21.48]$} & {$[17.89,21.12]$} \\
\hline & Severe & $24.17 * *$ & $24.38 * *$ & $23.08 * *$ & $26.25^{* *}$ & $21.49 * *$ \\
\hline & & {$[22.02,26.33]$} & {$[21.78,26.98]$} & {$[19.07,27.10]$} & {$[23.34,29.16]$} & {$[18.45,24.52]$} \\
\hline & Extreme & $31.39 * *$ & $31.96^{* *}$ & $29.93 * *$ & $30.65^{* *}$ & $32.63 * *$ \\
\hline & & {$[28.13,34.65]$} & {$[27.39,36.53]$} & {$[24.82,35.05]$} & {$[25.94,35.36]$} & [28.96,36.29] \\
\hline \multirow[t]{2}{*}{ Age (years) } & & $0.59 * *$ & $0.50 * *$ & $0.58 * *$ & $0.60 * *$ & $0.59 * *$ \\
\hline & & {$[0.53,0.64]$} & {$[0.37,0.63]$} & {$[0.43,0.73]$} & {$[0.51,0.68]$} & {$[0.53,0.65]$} \\
\hline \multirow[t]{3}{*}{ Sex } & Female & Ref. & Ref. & Ref. & Ref. & Ref. \\
\hline & Male & $-4.80^{* *}$ & $-4.92 * *$ & $-4.59 * *$ & $-6.22 * *$ & $-2.91 * *$ \\
\hline & & {$[-6.09,-3.51]$} & {$[-6.09,-3.76]$} & {$[-7.00,-2.19]$} & {$[-8.32,-4.12]$} & {$[-3.94,-1.88]$} \\
\hline \multirow[t]{7}{*}{ Education } & No formal & Ref. & Ref. & Ref. & Ref. & Ref. \\
\hline & Primary & $-4.07 * *$ & $-3.32 * *$ & $-5.59 * *$ & $-4.15 * *$ & $-2.43^{*}$ \\
\hline & & {$[-5.44,-2.70]$} & {$[-5.00,-1.64]$} & {$[-8.42,-2.75]$} & {$[-5.78,-2.51]$} & {$[-4.53,-0.33]$} \\
\hline & Secondary & $-7.01 * *$ & $-6.67 * *$ & $-7.87 * *$ & $-5.69 * *$ & $-6.09 * *$ \\
\hline & & {$[-8.60,-5.42]$} & {$[-8.61,-4.72]$} & {$[-11.42,-4.31]$} & {$[-7.89,-3.49]$} & {$[-8.50,-3.67]$} \\
\hline & Tertiary & $-11.38 * *$ & $-10.49 * *$ & $-12.09 * *$ & $-12.16^{* *}$ & $-9.54 * *$ \\
\hline & & {$[-13.64,-9.13]$} & {$[-12.87,-8.10]$} & {$[-16.45,-7.73]$} & {$[-15.29,-9.02]$} & {$[-12.67,-6.40]$} \\
\hline \multirow[t]{3}{*}{ Depression } & No & Ref. & Ref. & Ref. & Ref. & Ref. \\
\hline & Yes & $8.77 * *$ & $9.77 * *$ & $6.96 * *$ & $9.47 * *$ & $7.32 * *$ \\
\hline & & {$[6.72,10.81]$} & {$[7.52,12.03]$} & {$[3.75,10.18]$} & {$[6.59,12.34]$} & {$[5.14,9.51]$} \\
\hline \multirow[t]{2}{*}{ Perceived stress ${ }^{\mathrm{a}}$} & & $0.16^{* *}$ & $0.15^{* *}$ & $0.19 * *$ & $0.14 * *$ & $0.19 * *$ \\
\hline & & {$[0.14,0.19]$} & {$[0.12,0.17]$} & {$[0.15,0.23]$} & {$[0.11,0.18]$} & {$[0.17,0.22]$} \\
\hline
\end{tabular}

Abbreviation: LICs Low-income countries; MICs Middle-income countries; Ref Reference category

Data are b-coefficients [95\% confidence intervals].

Models are adjusted for all variables in the respective columns and country.

The outcome (subjective cognitive complaints score) ranged from 0 to 100 with higher scores representing greater cognitive complaints.

${ }^{a}$ The perceived stress score ranged from 0 to 100 with higher scores representing greater perceived stress.

$* \mathrm{p}<0.05, * * \mathrm{p}<0.001$ 
80

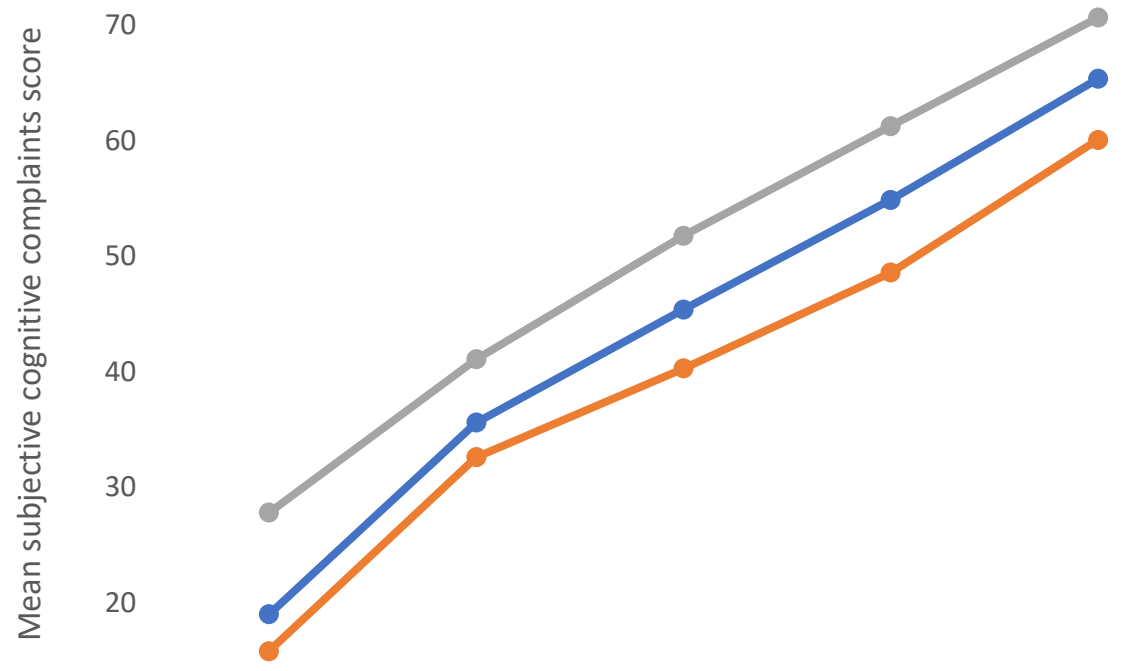

10

Sleep problem severity

\begin{tabular}{|c|c|c|c|c|c|}
\hline 0 & None & Mild & Moderate & Severe & Extreme \\
\hline$\longrightarrow$ Overall & 19 & 35.6 & 45.4 & 54.9 & 65.4 \\
\hline$\longrightarrow$ Age 50-64 y & 15.8 & 32.6 & 40.3 & 48.6 & 60.1 \\
\hline- Age $\geq 65 y$ & 27.8 & 41.1 & 51.8 & 61.3 & 70.7 \\
\hline
\end{tabular}

Figure 1 Mean subjective cognitive complaints score by severity of sleep problems The subjective cognitive complaints score ranged from 0 to 100 with higher scores representing greater cognitive complaints. 


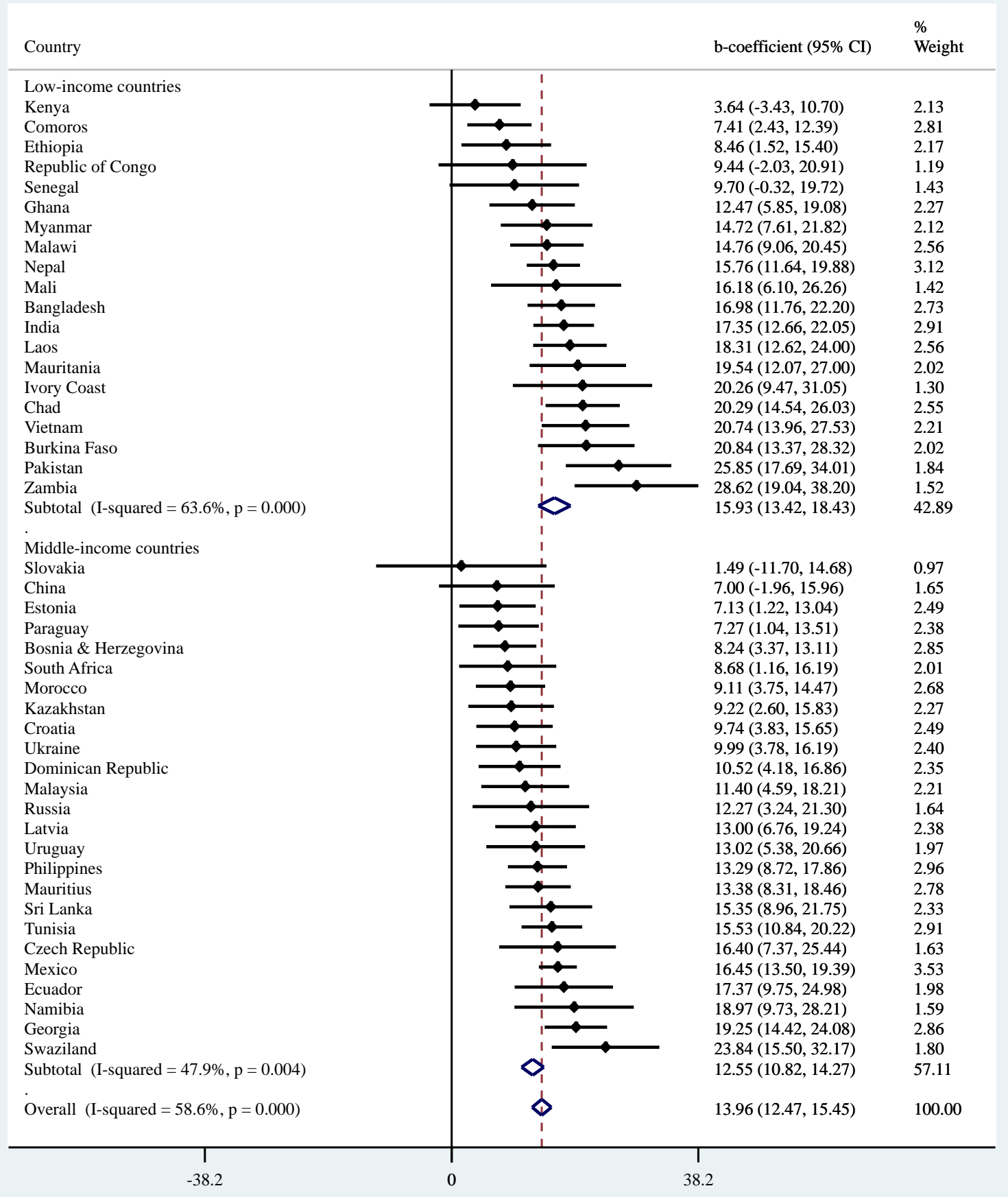

Figure 2 Country-wise association between severe/extreme sleep problems (exposure) and subjective cognitive complaints score among adults aged $\geq 50$ years estimated by multivariable linear regression

Abbreviation: CI Confidence interval

The subjective cognitive complaints score ranged from 0 to 100 with higher scores representing greater cognitive complaints.

Models are adjusted for age, sex, education, depression, and perceived stress.

Overall estimate was obtained by meta-analysis with random effects. 


\section{APPENDIX}

Table S1 Sample size by country

\begin{tabular}{|c|c|c|c|}
\hline Country & Age $\geq 50 y$ & Age 50-64 y & Age $\geq 65 y$ \\
\hline Bangladesh & 1,209 & 802 & 407 \\
\hline Bosnia \& Herzegovina & 440 & 233 & 207 \\
\hline Burkina Faso & 916 & 600 & 316 \\
\hline Chad & 1,020 & 611 & 409 \\
\hline China & 1,409 & 852 & 557 \\
\hline Comoros & 622 & 367 & 255 \\
\hline Croatia & 561 & 300 & 261 \\
\hline Czech Republic & 434 & 229 & 205 \\
\hline Dominican Republic & 1,355 & 809 & 546 \\
\hline Ecuador & 1,279 & 787 & 492 \\
\hline Estonia & 513 & 282 & 231 \\
\hline Ethiopia & 1,077 & 719 & 358 \\
\hline Georgia & 1,292 & 582 & 710 \\
\hline Ghana & 1,138 & 678 & 460 \\
\hline India & 2,558 & 1,721 & 837 \\
\hline Ivory Coast & 530 & 351 & 179 \\
\hline Kazakhstan & 1,109 & 819 & 290 \\
\hline Kenya & 965 & 587 & 378 \\
\hline Laos & 991 & 687 & 304 \\
\hline Latvia & 470 & 222 & 248 \\
\hline Malawi & 1,130 & 667 & 463 \\
\hline Malaysia & 1,652 & 1,154 & 498 \\
\hline Mali & 1,186 & 703 & 483 \\
\hline Mauritania & 971 & 653 & 318 \\
\hline Mauritius & 1,068 & 683 & 385 \\
\hline Mexico & 11,009 & 6,480 & 4,529 \\
\hline Morocco & 1,335 & 821 & 514 \\
\hline Myanmar & 1,606 & 1,012 & 594 \\
\hline Namibia & 877 & 501 & 376 \\
\hline Nepal & 2,117 & 1,362 & 755 \\
\hline Pakistan & 1,352 & 937 & 415 \\
\hline Paraguay & 1,321 & 807 & 514 \\
\hline Philippines & 2,230 & 1,544 & 686 \\
\hline Republic of Congo & 427 & 308 & 119 \\
\hline Russia & 2,307 & 1,017 & 1,290 \\
\hline Senegal & 764 & 517 & 247 \\
\hline Slovakia & 571 & 399 & 172 \\
\hline South Africa & 457 & 328 & 129 \\
\hline Sri Lanka & 1,906 & 1,275 & 631 \\
\hline Swaziland & 735 & 447 & 288 \\
\hline Tunisia & 1,393 & 731 & 662 \\
\hline Ukraine & 1,279 & 690 & 589 \\
\hline Uruguay & 1,182 & 653 & 529 \\
\hline Vietnam & 764 & 492 & 272 \\
\hline Zambia & 701 & 449 & 252 \\
\hline Total & 60,228 & 36,868 & 23,360 \\
\hline
\end{tabular}




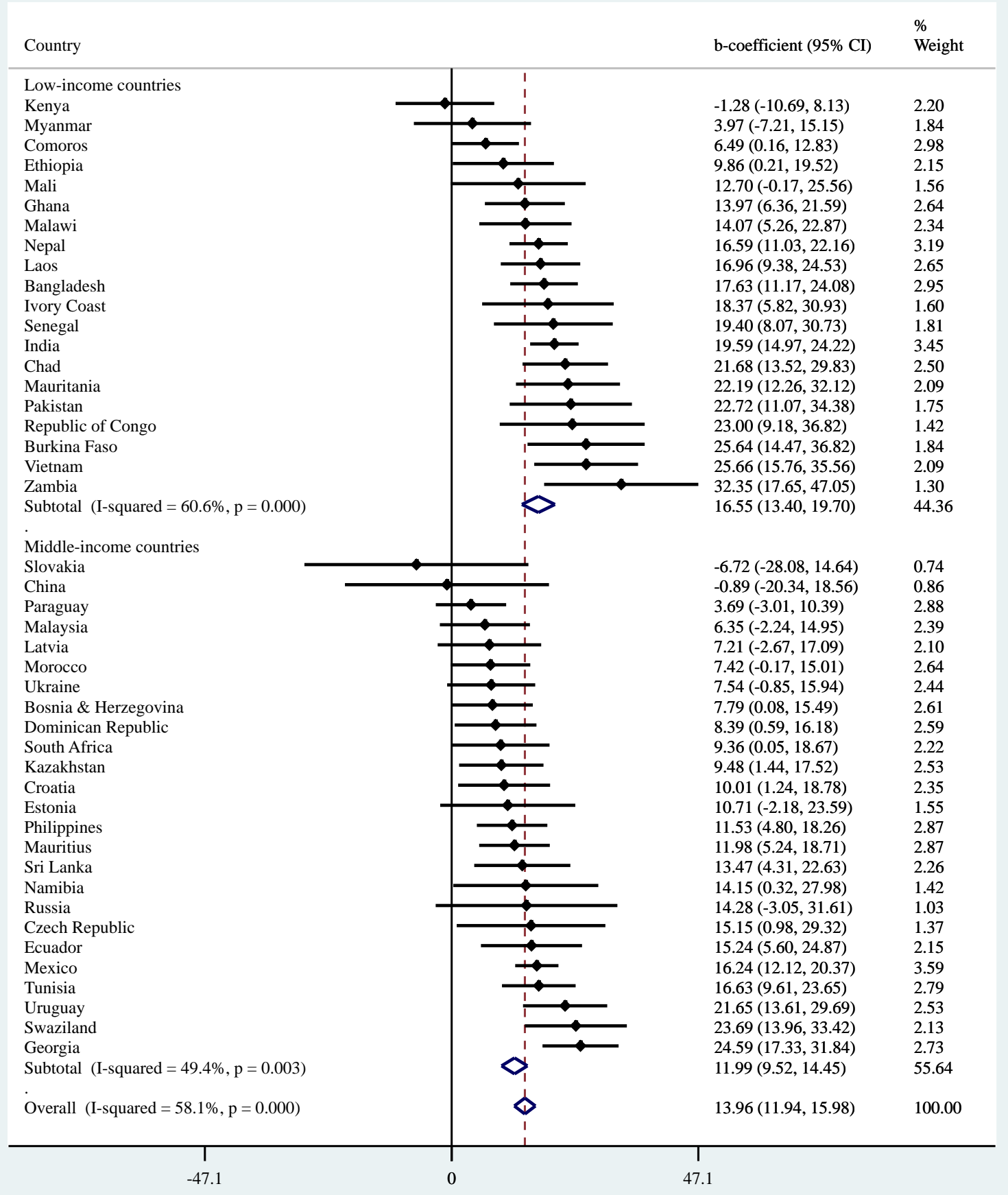

Figure S1 Country-wise association between severe/extreme sleep problems (exposure) and subjective cognitive complaints score among adults aged 50-64 years estimated by multivariable linear regression

Abbreviation: CI Confidence interval

The subjective cognitive complaints score ranged from 0 to 100 with higher scores representing greater cognitive complaints.

Models are adjusted for age, sex, education, depression, and perceived stress.

Overall estimate was obtained by meta-analysis with random effects. 


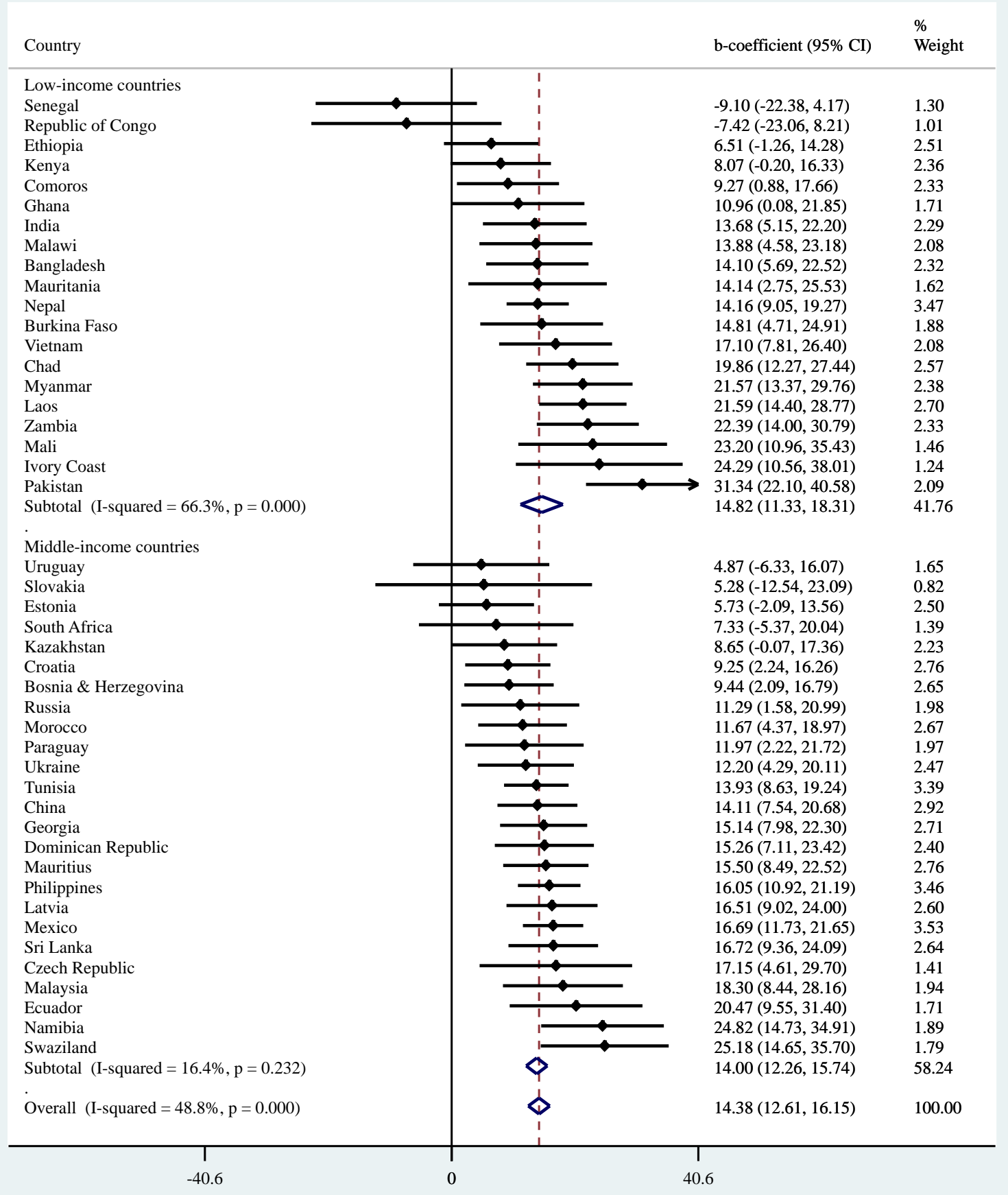

Figure S2 Country-wise association between severe/extreme sleep problems (exposure) and subjective cognitive complaints score among adults aged $\geq 65$ years estimated by multivariable linear regression

Abbreviation: CI Confidence interval

The subjective cognitive complaints score ranged from 0 to 100 with higher scores representing greater cognitive complaints.

Models are adjusted for age, sex, education, depression, and perceived stress.

Overall estimate was obtained by meta-analysis with random effects. 